\title{
O placebo e a Declaração de Pachuca: letras mortas?
}

\section{Resumo}

A Confederação Médica Latino-Americana e do Caribe, organização que congrega as entidades congêneres dos países da região, atua em defesa da profissão médica e da saúde da população, guiando-se por documentos internacionais. Em sua Assembleia Geral (Pachuca, México; 2013) foi aprovada a Declaração de Pachuca, com severas críticas à revisão da Declaração de Helsinki ocorrida no Brasil e aos ensaios clínicos que usam placebo em doenças com tratamento definido. $O$ tom duro e enérgico dessa Declaração propõe que entidades-membro denunciem os abusos éticos em todos os foros e aos governantes, e que atuem impedindo o uso do placebo nessas condições. Tais recomendações encontram respaldo no movimento mundial sobre integridade e ética na pesquisa. Conclui-se pela importância do papel educativo dos órgãos de fiscalização ética da medicina, alertando-se os médicos que infringirem essa orientação, a qual também integra o Código de Ética Médica, de que estarão sujeitos a processo ético-profissional.

Palavras-chave: Placebo. Declaração de Helsinki. Medicina. Pesquisa biomédica. Legislação médica. Integridade em pesquisa.

\section{Resumen}

\section{El placebo y la Declaración de Pachuca: ¿̇letras muertas?}

La Confederación Médica Latinoamericana y del Caribe (CONFEMEL), una organización que reúne a instituciones similares de los países de la región, actúa en defensa de la profesión médica y salud de la población, guiándose por los documentos internacionales. En su Asamblea General (Pachuca, México; 2013) se aprobó la Declaración de Pachuca con duras críticas a la revisión de la Declaración de Helsinki que tuvo lugar en Brasil y a los ensayos clínicos que utilizan placebo en enfermedades con tratamiento conocido. El tono duro y enérgico de tal Declaración propone que las entidades-miembros a denunciar los abusos éticos en todos los foros y a los gobernantes, y que actúen impidiendo el uso del placebo en estas circunstancias. Estas recomendaciones se apoyan en el movimiento mundial sobre Integridad y ética en la investigación. Se concluye sobre la importancia del papel educativo de los órganos de supervisión ética da medicina, alertando a los médicos que violen esta norma, que también está contemplada en el Código de Ética Médica, que estarán sujetos a proceso ético-profesional.

Palabras-clave: Placebo. Declaración de Helsinki. Medicina. Investigación biomédica. Legislación médica. Integridad en investigación.

\section{Abstract \\ The placebo and the Declaration of Pachuca: dead letters?}

The Latin American and Caribbean Medical Confederation (CONFEMEL), an organization that brings together related organizations from countries of the region, works on behalf of the medical profession and the population's health guided by international documents. During its General Assembly (Pachuca, Mexico; 2013) the Declaration of Pachuca was approved with strong critics regarding the review of the Declaration of Helsinki that occurred in Brazil and the issue of clinical trials that use placebo in diseases with known treatment. The strong and energetic tone of this Declaration proposes that member entities condemn ethical abuses in all forums and also to administrations so that they engage against the use of placebo in these conditions. These recommendations are supported in the global movement on Integrity and Ethics in Research. The conclusion addresses the importance of the educative role of ethical supervision of Medicine warning physicians who violate these guidelines, which are also incorporated in the Code of Medical Ethics, that they will be subjected to ethical-professional process.

Keywords: Placebo. Declaration of Helsinki. Medicine. Biomedical research. Medical legislation. Integrity in research.

Doutor schlemper.junior@gmail.com - Universidade do Oeste de Santa Catarina, Joaçaba/SC, Brasil.

\section{Correspondência}

Rua Frei Evaristo, 64/ 202 CEP 88015-410. Florianópolis/SC, Brasil.

Declara não haver conflito de interesse. 


\section{A Confemel}

Os conselhos federais e os colégios de medicina dos países da América Latina e Caribe criaram, em 1997, a Confederação Médica Latino-Americana e do Caribe (Confemel), entidade médica não governamental, sem fins lucrativos, com o objetivo, entre outros, de atuar a favor da saúde das populações, do ponto de vista humano, científico, tecnológico e político. A Confemel é regida pelos princípios de universalidade, integralidade, equidade e acessibilidade, ou seja, tem como premissa que a atenção médica deve ser universal, integral, equitativa e igualitária, proporcionando oportunidade de acesso com qualidade e cordialidade. Além disso, sua ação é guiada por vários documentos internacionais, entre eles a Declaração de Helsinki (DoH), de 1964, modificada na Escócia no ano $2000^{1}$. A confederação congrega entidades médicas de 19 países da região, entre eles os seis que mais realizam ensaios clínicos na América Latina, como registrado na plataforma internacional clinicaltrial.gov: Brasil, México, Argentina, Chile, Colômbia e Peru. Por parte do Brasil, integram a Confemel os três entes médicos nacionais: Conselho Federal de Medicina, Associação Médica Brasileira e Federação Nacional dos Médicos.

A Confemel se reúne anualmente em assembleia geral, quando são tomadas deliberações sobre temas agudos da saúde humana que afligem as populações e os médicos da região. Assim, em sua 11a Assembleia Anual Ordinária, em 2008, foi aprovada a Declaración de Buenos Aires sobre Investigaciones Médicas, com duras críticas às modificações da DoH introduzidas no mesmo ano em Seul, Coreia do Sul, pela Associação Médica Mundial (AMM), sobretudo em relação ao duplo standard, e na qual conclui su firme compromiso a accionar ante los gobiernos de los países que la constituyen, para evitar su aplicación ${ }^{2}$. A última dessas assembleias, a 16a de sua história de lutas e avanços, ocorreu na cidade mexicana de Pachuca em novembro de 2013, quando foi discutido um tema polêmico, antigo, mas que continua atual, relacionado ao uso de placebo no braço-controle de ensaios clínicos.

O placebo e a Declaração de Helsinki de 2013 - Fortaleza, Ceará, Brasil

0 assunto da 16 assembleia dizia respeito, especificamente, ao ocorrido um mês antes na cidade de Fortaleza, Ceará, Brasil, quando a AMM aprovou a nova Declaração de Helsinki (DoH 2013) ${ }^{3}$, cujo texto sobre o uso do placebo foi flexibilizado de forma inadequada. $O$ documento cria possibilidades de uso irrestrito do placebo, camuflado nas velhas e eticamente questionadas razões metodológicas convincentes e cientificamente sólidas. Além disso, a DoH 2013 aceita qualquer intervenção menos efetiva que a melhor comprovada, quando for necessário para determinar a eficácia ou segurança de uma intervenção ${ }^{3}$. A frase final sobre o uso do placebo, recomendando que extremo cuidado deve ser tomado para evitar abuso desta opção, soa como advertência inútil e relegada ao esquecimento. Essa parte do texto da DoH sobre o placebo parece ser a que mais causou repulsa e indignação às entidades médicas da Confemel presentes na 16a Assembleia, o que acabou gerando os termos da Declaração de Pachuca ${ }^{4}$.

\section{A Declaração de Pachuca}

Expressão da classe médica, a Declaração de Pachuca sobre a revisão de Helsinki ${ }^{4}$ foi aprovada em 22 de novembro de 2013, no âmbito da 16a Assembleia da Confemel, e ratificou, por unanimidade, a Declaração de Bogotá, emitida pela mesma organização em 2012, quando já havia se manifestado contrária ao uso do placebo, como segue: En ese sentido, se opone incondicionalmente a los artículos 32 y 33 de la Declaración de Helsinki sobre la investigación en seres humanos de la Asociación Medica Mundial ya que entiende que este tipo de investigación con placebo es contraria a los principios y valores de la profesión y de la ética médica ${ }^{5}$

Por sua vez, a Declaração de Pachuca foi aprovada nos seguintes termos: rechaza rotunda y unánimemente cualquier investigación médica en seres humanos que utilice el placebo cuando exista una medicación de eficacia demostrada para la patología en estudio. Las poblaciones pobres y vulnerables, discriminadas por su falta de recursos no pueden ser sometidas a investigaciones biomédicas que cuenten con niveles de seguridad inferiores a los aplicados a las sociedades con mayor desarrollo ${ }^{4}$.

O documento, ao tecer críticas à DoH 2013, aprovado no Brasil, ainda assinala que: c) En lo que refiere al punto 33, la utilización de placebo cuando existen intervenciones probadas y efectivas es contraria a los principios y valores de la profesión y de la ética médica. [...] e) Como acción inmediata se propone a los respectivos gobiernos no autorizar ni financiar los medicamentos que hayan utilizado 
en su evaluación placebo existiendo mejores intervenciones probadas. f) Las Asociaciones miembro nos comprometemos a denunciar esta situación en todas las instancias y foros nacionales e internacionales así como ante nuestros gobiernos y a realizar todas las acciones institucionales de CONFEMEL para impedir la aplicación de esta norma en la investigación médica ${ }^{4}$.

Interessa ressaltar a forte revolta dos órgãos fiscalizadores da prática médica na América Latina e no Caribe sobre a flexibilização do uso do placebo inserida na $\mathrm{DoH} 2013$, a ponto de, pela primeira vez, se propor que os governos não permitam ensaios com esse viés ético e que se denuncie essa situação em todos os níveis do poder público para impedir sua aplicação em nosso território.

\section{A liderança do Brasil e o papel do Conselho Federal de Medicina no uso ético do placebo}

O Brasil, há tempos, tem o reconhecimento da comunidade nacional e internacional ligada à DoH, em especial pela forte e permanente atuação do Conselho Federal de Medicina (CFM) na defesa do uso ético do placebo ${ }^{6}$. No Brasil, a AMM sempre encontrou pronta aceitação da $\mathrm{DoH}$, pois o CFM foi a primeira entidade nacional a respaldá-la, transformando suas orientações em norma ética profissional a ser seguida pela categoria médica sob sua jurisdição em matéria de pesquisa clínica, por meio da Resolução 671/1975 7 .

Porém, a revisão da DoH de 2008 não contou com o apoio do CFM, em virtude de terem sido criadas alternativas para o uso não ético do placebo. A posição firme e contrária ocorreu ainda durante a assembleia da AMM em Seul, quando o então presidente do Conselho Federal de Medicina se manifestou de forma crítica e contundente contra o texto aprovado, que permitiu a flexibilização do uso do placebo ${ }^{8}$. Em função dessa vigorosa e oportuna manifestação contra os termos da DoH 2008 quanto à flexibilização do uso do placebo, entende-se ser importante registrá-la para a história com suas palavras no idioma oficial da AMM, como segue:

\section{Esteemed Colleagues,}

Today we are here together and at the point of ending two years of work on the modification of the Declaration of Helsinki. This key document is for us the most important manifestation of our commitment in the field of human ethics. There are other documents, which are part of our tradition, but none have the dimensions, the impact, and the level of acceptance as the Declaration of Helsinki. The Declaration of Helsinki is a liberating document, which puts the World Medical Association in the forefront of the defense of human rights by demanding that the highest ethical and scientific standards be used when research takes place in human subjects. The Declaration of Helsinki protects not only those who participate in research, but also all human beings because it demands that the results from this research be of quality. The Declaration of Helsinki, as a protector, keeps the beautiful structure of medicine on a firm foundation, strengthening it to be what it must be - able to offer care based on science and ethical conduct. This is my message which comes to you from my heart, and I say this without concern for the emotion that I feel, because I cannot understand medicine without compassion or the provision of care unaccompanied by love, and l ask you "What are the scientific reasons that can justify the ethical-scientific use of placebo in research with human beings that have not been discussed by Professor Dr. José Luis Gomes do Amaral and which we are defending in the forum of this Association? What is the scientific evidence for change? Where are the irrefutable voices of scientific knowledge leading us to impose change without having to weaken the structure of our beautiful profession? There is only silence. There are no voices, because this evidence does not exist. We cannot rest here. Brazil proposes to this illustrious Assembly that, with no scientific evidence to modify, justify, or relax the ethical standards governing the use of placebo in research with human subjects, and with the necessity of maintaining the highest level of our professional ethics in defending human interest - which is the only justification for the practice of medicine - we do not approve the modifications to Article 29 of the Declaration of Helsinki as they have been presented to us by the Director of the World Medical Association, and we retain the professional standing that deserves the respect of humanity.

Signed: Edson de Oliveira Andrade, President of the CFM $^{9}$.

Em decorrência disso, quatro dias depois, o CFM editou a Resolução 1.885/2008 ${ }^{10} \mathrm{com}$ as restrições éticas necessárias ao uso de placebo, proibindo os médicos brasileiros de participar de ensaios clínicos quando houver tratamento efetivo para a doença pesquisada. Pela veemência das justificativas e importância de seu valor histórico, vale reproduzir o inteiro teor do documento ético que condena o uso abusivo do placebo em ensaios com novas drogas: 
Considerando o decidido na Assembleia Geral de 2008 da Associação Médica Mundial, realizada nos dias 15 a 18 de outubro, em Seul - Coreia do Sul, que alterou o artigo 29 da Declaração de Helsinki, permitindo o uso de placebo mesmo havendo tratamento reconhecidamente eficaz, por razões metodológicas; Considerando não haver evidências científicas que justifiquem a complacência ética adotada no uso de placebo pela alteração da atual Declaração de Helsinki; Considerando a não aprovação pela representação médica brasileira das alterações propostas para a nova redação do artigo 29 da Declaração de Helsinki (revisão 2004), renumerado para o artigo 32 na Assembleia de Seul, Coreia do Sul; Considerando o decidido em sessão plenária de 23 de outubro de 2008, Resolve: Art. $1^{\circ}$ É vedado ao médico vínculo de qualquer natureza com pesquisas médicas envolvendo seres humanos, que utilizem placebo em seus experimentos, quando houver tratamento eficaz $e$ efetivo para a doença pesquisada ${ }^{10}$.

No ano seguinte, em 2009, reconhecendo a importância de se manter esse freio ético aos médicos pesquisadores que atuam em ensaios clínicos no país, o teor desse documento foi integralmente mantido no Código de Ética Médica (CEM), materializado na Resolução CFM 1.931/2009 ${ }^{11}$, corroborando sua posição anterior sobre as restrições ao uso do placebo.

A par da permanente atuação do CFM, outras entidades, como o Conselho Nacional de Saúde (CNS), Comissão Nacional de Ética em Pesquisa (Conep) e Sociedade Brasileira de Bioética, também estiveram sempre presentes nos momentos mais delicados, quer pela edição de resoluções normativas, quer pela aprovação de moções de apoio irrestrito à luta contra a falência ética na utilização incontrolada do placebo. Essa atuação deve ser permanente pelo crescente incremento das pesquisas com novos fármacos no Brasil, uma vez que se demonstrou que o país tem um futuro promissor em pesquisa e desenvolvimento na área farmacêutica ${ }^{12}$.

\section{O uso do placebo e o descaso com as normas éticas no Brasil}

No entanto, em que pese a vigência do CEM e das demais normas éticas, parece que alguns médicos pesquisadores insistem em ignorá-las, e continuam a usar placebo em doenças para as quais existe enorme gama de medicamentos eficazes disponíveis. Em levantamento dos ensaios clínicos com drogas de fase III para qualquer doença e registrados na plataforma clinicaltrials.gov por dez anos, sendo cinco antes e cinco depois de 2008 , concluiu-se pela ineficácia das restrições éticas determinadas pelo CFM, bem como daquelas que constam das resoluções do Conselho Nacional de Saúde (CNS), haja vista que o percentual de uso do placebo, quando comparados os dois períodos, foi semelhante e que, nos estudos com patrocínios de instituições universitárias, empresas nacionais e outras, ocorreu aumento significativo após $2008^{13}$.

Exemplo mais contundente do não cumprimento do CEM foi observado nos ensaios clínicos de fase III em pacientes com diabetes tipo 2, registrados no clinicaltrials.gov, patrocinados pela indústria farmacêutica e nos quais em 51,6\% (93/48) dos estudos realizados no Brasil, entre 2003 e 2013, foi usado placebo como braço controlador. Desnecessário enfatizar a gama de medicamentos disponíveis para a terapêutica dessa doença e, mesmo assim, em mais da metade dos estudos, o braço-controle continha placebo, o que se configura infração ética. Inimaginável que isso esteja acontecendo com participantes brasileiros, que deveriam estar igualmente amparados pelas resoluções do Conselho Nacional de Saúde.

Esses dados foram levantados na referida plataforma on-line, em que foi possível obter o total das intervenções por drogas em diabetes 2 no período em referência pela inserção dos descritores nos ícones Find Studies e Advanced Search: "drug"; "excluded Unknown"; "Interventional Studies"; "diabetes 2"; "Brazil"; "Child, Adult, Senior"; "Phase 3"; "Industry"; "received from 01/01/2003 to $12 / 31 / 2013$ ". Por sua vez, para obter o número desses ensaios com placebo, inseriu-se esta palavra nos mesmos ícones Find Studies e Advanced Search: "drug"; "excluded Unknown"; "Interventional Studies"; "diabetes 2"; "placebo"; "Brazil"; "Child, Adult, Senior"; "Phase 3"; "Industry"; "received from $1 / 1 / 2003$ to $12 / 31 / 2013$ ".

Alerta-se, ainda, que as pesquisas em diabetes, em virtude da evolução crônica dessa doença, têm vários anos de uso do placebo no grupo-controle. Os dados desses levantamentos do clinicaltrials.gov, sobretudo os estudos em diabetes 2 , se contrapõem frontalmente à visão de que a proibição do CFM teria engessado as pesquisas com placebo no Brasil a partir da aprovação da Resolução CFM 1.885/2008, conforme argumentado por alguns grupos de pesquisadores ${ }^{14}$. Interessante que a justificativa para essa argumentação refere que, se o placebo não é ético, tais pesquisas estão, a partir de 23 de outubro de 2008, inviabilizadas, uma vez que não se podem 
usar dados obtidos de forma antiética para a publicação científica ${ }^{15}$.

Como é sabido, os estudos com patrocínio das indústrias multinacionais têm seus protocolos elaborados no exterior, cabendo aos médicos especialistas no Brasil aceitar ou não participar quando convidados. Pelos números referidos, parece que muitos concordam em atuar como responsáveis nos seus centros de pesquisa clínica, ignorando as proibições do CEM, o que está a merecer rigorosa fiscalização por parte dos conselhos regionais de medicina, em particular daqueles com jurisdição nos grandes centros urbanos e que contam com o maior número de centros de pesquisa.

Em sua maior parte, esses centros estão localizados em São Paulo (37), Porto Alegre (13), Rio de Janeiro (10), Belo Horizonte (10), Campinas (9) e Curitiba (7), segundo dados de 2005 a $2009{ }^{12}$. Por sua vez, os ensaios clínicos com grupo placebo-controlado são mais baratos porque exigem amostra menor e infraestrutura menos onerosa do que os ensaios em que o grupo-controle é tratado com medicamentos já disponíveis no mercado ${ }^{9}$.

Deve-se acrescentar que tanto a $\mathrm{DoH} 2008$ quanto a DoH 2013 mereceram sérias restrições quanto ao texto sobre o uso do placebo, não só por parte do Conselho Federal de Medicina, mas também da Comissão Nacional de Ética em Pesquisa (Conep) do Conselho Nacional de Saúde, por meio da Resolução CNS 404/2008 ${ }^{16}$ (revogada pela Resolução CNS 466/2012), da Sociedade Brasileira de Bioética e de prestigiados bioeticistas latino-americanos ${ }^{17-19}$. Um deles ${ }^{19}$, ampliando sua indignação contra a DoH 2013, propôs que a América Latina abandone a DoH e crie seu próprio documento ético, voltado para a nossa realidade.

Nada ilógico nessa proposta, se considerarmos que os Estados Unidos, por meio da Food and Drug Administration (FDA) abandonaram a DoH em outubro de 2008, substituindo-a pelo Good Clinical Practices/International Conference on Harmonization (GCP/ICH), de 1996. Como se sabe, esse documento destina-se a harmonizar os procedimentos metodológicos entre Estados Unidos, Europa e Japão, para facilitar a aceitação mútua dos ensaios clínicos por suas agências reguladoras ${ }^{18}$, não sendo, portanto, um documento ético, razão pela qual não pode ser o substituto da DoH.

No Brasil, porém, nem todos comungam da mesma opinião defendida pelo CFM e pela Conep, haja vista que a Associação Médica Brasileira (AMB) aprovou o texto da DoH 2008 adotado na reunião de Seul, ao concluir que: Temos, portanto, um documento bastante sólido, atualizado e disponivel para o balizamento ético ${ }^{20}$. Da mesma forma, na revisão da DoH de Fortaleza (2013), o representante da AMB avaliou que: $A A M B$ reconhece a importância da $\mathrm{DoH}$ como um conjunto de princípios éticos consumado por sociedades médicas de todo o mundo e entende que o Brasil necessita estar alinhado com todos os países onde pesquisas são feitas ${ }^{21}$. Percebe-se, assim, que existe histórica divergência nacional entre a posição da $\mathrm{AMB}$, alinhada e signatária da DoH, e aquela adotada ao longo dos anos pelo CFM e pela Conep ${ }^{15}$.

\section{A Declaração de Pachuca e o movimento mun- dial pela integridade e ética na pesquisa}

Uma conexão interessante pode ser estabelecida entre a Declaração de Pachuca e o movimento mundial iniciado por pesquisadores de vários países preocupados com as questões éticas, morais e de honestidade que crescem assustadoramente no campo das ciências. Fruto dessas preocupações, a 1a Conferência Mundial sobre Integridade em Pesquisa ( $1^{\text {st }}$ World Conference on Research Integrity) foi realizada em Portugal, em 2007; a 2ª em Cingapura, em 2010; a 3a no Canadá, em 2012; e a 4a Conferência ocorrerá no Brasil, mais precisamente na cidade do Rio de Janeiro, em $2015^{22}$.

No Brasil, as primeiras iniciativas para estabelecer um fórum de discussão e debates sobre o tema da integridade, da ética e da responsabilidade em pesquisa foram o 10 Encontro Brasileiro sobre Integridade em Pesquisa, Ética na Ciência e em Publicações ( $1^{\text {st }}$ Brazilian Meeting on Research Integrity, Science and Publication Ethics - Brispe) ${ }^{23}$, ocorrido em 2010, e o 20 Brispe ${ }^{24}$, realizado em 2012, tendo o primeiro o apoio da Sociedade Brasileira de Bioética na divulgação do evento. Ambos tinham como eixo norteador a promoção da divulgação do tema da ética e integridade junto às instituições de pesquisa e do processo educativo dos pesquisadores, sobretudo dos estudantes e dos jovens pesquisadores.

Para melhor esclarecer essa questão da integridade, vale reproduzir as palavras de Santos, que muito bem sintetizam o real significado dessa temática: A expressão "integridade da pesquisa" (research integrity) vem sendo utilizada para demarcar um campo particular no interior da ética profissional do cientista, entendida como a esfera total dos deveres éticos a que o cientista está submetido ao realizar suas atividades propriamente científicas. No interior dessa esfera, pode-se distinguir, por um 
lado, o conjunto dos deveres derivados de valores éticos mais universais que os especificamente científicos. São dessa natureza aqueles que compõem o campo da chamada Bioética, derivados, por exemplo, do valor (não especificamente científico) que é o respeito à integridade física, psicológica e moral dos seres humanos ${ }^{25}$.

Ora, por abordar um campo próprio da ética profissional do pesquisador, nada mais lógico que o assunto seja incluído no raio de ação dos códigos deontológicos das diversas profissões da saúde, por envolver valores éticos como a beneficência, a não maleficência, a imprudência e a negligência, diretamente relacionados com o uso do placebo nos ensaios clínicos. Acrescente-se a eles o princípio da justiça, uma vez que a todos os envolvidos no estudo devem ser oferecidos os mesmos direitos de acesso aos melhores tratamentos possíveis.

A esse propósito, é interessante o editorial da Revista da Associação Médica Brasileira ${ }^{26}$, que, ao tratar do uso do placebo, refere que a dissimulação terapêutica, em princípio, não trará nenhum benefício direto a quem o utilizar e questiona por que o médico incluiria paciente seu em estudo no qual não venha a obter benefício direto da pesquisa. $O$ editorial ainda sugere que, em caso de dano ao paciente que utiliza placebo, é possível ter havido imprudência ou negligência por parte do profissional, pois os médicos sabem dos riscos da utilização do placebo nas doenças cujo tratamento é conhecido.

Nesse caso, pode-se supor que o médico estaria infringindo o Código de Ética Médica, que no artigo 1 o do Capítulo III, que trata da responsabilidade profissional do CEM, veda: Causar dano ao paciente, por ação ou omissão, caracterizável como imperícia, imprudência ou negligência. Além disso, certamente estaria desrespeitando também o seu artigo 106, que proíbe ao médico: Manter vínculo de qualquer natureza com pesquisas médicas, envolvendo seres humanos, que usem placebo em seus experimentos, quando houver tratamento eficaz $e$ efetivo para a doença pesquisada ${ }^{11}$.

A sanção ética, nesse caso, pretenderia manter os elevados padrões éticos da medicina, com respeito e defesa dos direitos dos pacientes, única e verdadeira razão de ser da medicina. Por outro lado, em que pese a clara infração ética por parte de médicos brasileiros que aceitam participar de ensaios clínicos envolvendo o uso de placebo em doenças de tratamento reconhecido, ao que se saiba, não há registro de denúncia ou instauração de processo ético-profissional por não obediência aos cuidados no uso do placebo nos conselhos regionais ou Federal de Medicina. As ações do pesquisador que, por intenção ou negligência, contrariam esses pressupostos constituem condutas eticamente inadequadas do ponto de vista da integridade da pesquisa ${ }^{25}$. Ou seja, nos ensaios envolvendo o uso do placebo em claro desrespeito às normas nacionais e internacionais, pode-se considerar que 0 pesquisador e os patrocinadores desses estudos estão cometendo um erro que, além de ser contrário à ética, pode ser classificado como conduta não íntegra.

Dessa forma, depreende-se que há uma perfeita interação dos termos da Declaração de Pachuca com o tema da integridade e ética em pesquisa. No Brasil, além dos dois Brispe, ocorreu, pela primeira vez, a manifestação formal do Conselho Nacional de Desenvolvimento Científico e Tecnológico (CNPq) ao criar uma Comissão Especial para propor recomendações e diretrizes éticas sobre o tema. Das várias diretrizes propostas pelo órgão, a última delas sintetiza todas as necessidades éticas de uma pesquisa científica: Todo trabalho de pesquisa deve ser conduzido dentro de padrões éticos na sua execução, seja com animais ou com seres humanos ${ }^{27}$.

Da mesma forma, a Fundação de Amparo à Pesquisa do Estado de São Paulo (Fapesp), que também aderiu a esse movimento de ética e integridade, sendo a primeira agência brasileira de fomento à pesquisa a aprovar um Código de Boas Práticas em Pesquisa, descreve claramente a má conduta científica [como sendo] toda conduta de um pesquisador que, por intenção ou negligência, transgrida os valores e princípios que definem a integridade ética da pesquisa cientifica ${ }^{28}$. Compreende-se, assim, que o uso deliberado e consciente do placebo nos ensaios clínicos nas situações acima referidas pode ser considerado má conduta científica por desrespeito às normas éticas identificadas anteriormente.

Em continuação a esse processo educativo, Spink ${ }^{29}$, em esclarecedora análise sobre a ética na pesquisa científica, assinala que o primeiro desafio a ser enfrentado decorre da crescente subordinação da ciência a poderosos grupos econômicos privados, os quais têm os meios para orientar resultados conforme seus interesses. O autor cita, entre outros, que o uso de populações vulneráveis em ensaios clínicos é fator relacionado com a crescente preocupação sobre as questões éticas nas ciências. Essa é uma prática de ocorrência frequente nos ensaios clínicos conduzidos no Brasil ${ }^{9}$. 


\section{Considerações finais}

Tendo em vista a orientação da Declaração de Pachuca de que suas instituições filiadas deverão atuar com mais rigor no sentido de impedir a realização de ensaios clínicos com placebo eticamente não justificável, espera-se que - se essa diretriz for colocada em prática pelas instituições que a subscreveram, como é o caso das entidades do Brasil -, a partir de agora, o atual cenário de liberdade científica, mas de conduta ética questionável, venha a ser mais fiscalizado e os médicos, mais bem orientados.

Acredita-se que o leque de atuação poderá situar essas ações em três níveis da área médica: a) ações educativas, com a implantação de medidas preventivas e pedagógicas a serem desencadeadas junto aos pesquisadores, instituições universitárias e centros de pesquisa clínica no país, seja por meio de eventos, normas ou outras atividades similares; b) ações de fiscalização dos centros de pesquisa clínica; c) ações de desestímulo ao uso não ético do placebo, inclusive abertura de processo ético-disciplinar, se for o caso.

A primeira delas deve ser a mais exequível e mais fácil, haja vista os inúmeros mecanismos de acesso aos médicos, seja por meio de endereços eletrônicos, de boletins, revistas e outras formas. Já, para desenvolver o segundo nível de ação, é preciso reportar-se à recente Resolução CFM 2.056/2013, que estabelece critérios para a autorização de funcionamento dos serviços médicos de quaisquer naturezas e estabelece critérios mínimos para seu funcionamento ético ${ }^{30}$.

Além disso, a Resolução CFM 2.056/2013 atribui aos diretores médicos investidos em funções administrativas a corresponsabilidade, quando de- vidamente cientificados, no caso de a prática da medicina se fizer em desacordo com essa norma. $O$ parágrafo único de seu artigo 21 é explícito ao determinar que: Esta responsabilização alcança a inércia em permitir a persistência de condições degradantes à assistência aos pacientes, à realização de pesquisas em pacientes sem autorização de Comitê de Ética em Pesquisa e a utilização de procedimentos considerados não válidos pelo Conselho Federal de Medicina ${ }^{30}$.

Em outras palavras, quando se trata do uso do placebo em situação não autorizada pelo CEM, esses diretores médicos, no cumprimento de suas obrigações, deveriam atuar na prevenção e na fiscalização do exercício ético da profissão nos ensaios clínicos, por ser essa uma atividade médica. Portanto, a Resolução CFM 2.056/2013 representa um novo e importante instrumento ético para controlar o uso indiscriminado e injustificável do placebo.

Finalmente, entende-se, igualmente, que a Declaração de Pachuca, ao propor ações globais junto aos setores públicos e privados responsáveis pelo financiamento dos estudos e pelo sistema ético de aprovação dos ensaios clínicos, como somatório no esforço de proteção dos participantes dos ensaios clínicos, deveria encontrar eco por parte de suas entidades filiadas. Espera-se que as palavras da Declaração de Pachuca e do artigo 106 do Código de Ética Médica não se transformem em letras mortas, sob pena de jogar por terra o enorme esforço despendido ao longo dos últimos anos pelas entidades brasileiras na defesa dos participantes e do exercício ético dos médicos em pesquisas clínicas, em particular nos cuidados e na exigência do uso adequado do placebo.

\section{Referências}

1. Confederación Médica Latinoamericana y del Caribe (Confemel). Estatuto. [Internet]. [acesso 18 jul 2014]. Disponível: http://www.confemel.com/estatutos/estatutos_2010.pdf

2. Confederación Médica Latinoamericana y del Caribe (Confemel). Declaración de Buenos Aires sobre Investigaciones Médicas. [Internet]. 11a Asamblea Anual Ordinaria; Buenos Aires; 5-7 nov 2008 [acesso 18 jul 2014]. Disponível: http://www.confemel.com/asambleas/xiasam_bsas08_4.htm

3. World Medical Association. Declaration of Helsinki. Ethical principles for medical research involving human subjects. [Internet]. 64th WMA General Assembly; Fortaleza, Brazil; out 2013 [acesso 16 jun 2014]. Disponível: http://www.wma.net/en/30publications/10policies/b3/index.html

4. Confederación Médica Latinoamericana y del Caribe (Confemel). Declaración de Pachuca sobre la revisión de Helsinki. [Internet]. 16a Asamblea General Ordinaria; Pachuca, México; 20-23 nov 2013 [acesso 18 jun 2014]. Disponível: http://www.confemel.com/asambleas/xviaao/ declaracion_helsinki.pdf

5. Confederación Médica Latinoamericana y del Caribe (Confemel). Declaración de Bogotá sobre investigación médica en seres humanos. [Internet]. 15a Asamblea General Ordinaria; Bogotá, Colombia; 21-23 nov 2012 [acesso 18 jun 2014]. Disponível: http://www.confemel.com/ asambleas/xvaao/declaracion_bogota.pdf 
6. Schlemper Junior BR, Hellmann F. Controvérsias em tempos de mudanças na Declaração de Helsinque e a experiência brasileira em ética em pesquisa. In: Brzozowski FS, Hellmann F, Verdi M, Caponi S. Medicalização da vida: ética, saúde pública e indústria farmacêutica. 2 a ed. Curitiba: Prismas; 2013. p. 37-66.

7. Conselho Federal de Medicina. Resolução no 671, de 18 de julho de 1975. Considera a Declaração de Helsinque adotada pela Associação Médica Mundial como guia a ser seguido pela classe médica em matéria referente à pesquisa clínica. [acesso 20 ago 2014]. Disponível: http://www. portalmedico.org.br/resolucoes/CFM/1975/671_1975.htm

8. Schlemper Junior BR. Historia del control ético de la investigación en seres humanos en Brasil. Fármacos. [Internet]. 2008 [acesso 20 ago 2014];11(5):9-10. Disponível: http://www. saludyfarmacos.org/wp-content/files//nov08.pdf

9. Freitas CBD, Schlemper Junior BR. Progress and challenges of clinical research with new medications in Brazil. In: Homedes N, Ugalde A, organizadores. Clinical trials in Latin America: where ethics and business clash. Londres: Springer; 2014. p. 151-71.

10. Conselho Federal de Medicina. Resolução no 1.885, de 23 de outubro de 2008 . Veda ao médico participar de pesquisa envolvendo seres humanos utilizando placebo quando existir tratamento disponível eficaz já conhecido. 22 out 2008 [acesso 20 ago 2014]. Disponível: http://portalmedico. org.br/resolucoes/CFM/2008/1885_2008.htm

11. Conselho Federal de Medicina. Resolução no 1.931, de 17 de setembro de 2009. Aprova o Código de Ética Médica. 24 set 2009 [acesso ago 2014]. Disponível: http://www.portalmedico.org.br/ resolucoes/CFM/2009/1931_2009.pdf

12. Zucchetti C, Morrone FB. Perfil da pesquisa clínica no Brasil. Revista HCPA. 2012;32(3):340-7.

13. Rubenich GB, Heck S, Hellmann F, Schlemper Junior BR. O uso do placebo em ensaios clínicos multicêntricos no Brasil [TCC]. Joaçaba, Santa Catarina: Universidade do Oeste de Santa Catarina, Faculdade de Medicina; 2014.

14. Sousa MSA, Franco MAG, Massud Filho J. A nova declaração de Helsinque e o uso de placebo em estudos clínicos no Brasil: a polêmica continua. Rev Med (São Paulo). 2012;91(3):178-88.

15. Sousa MAS, Franco MAG, Massud Filho J. Op. cit. p. 186.

16. Conselho Nacional de Saúde (Brasil). Resolução CNS no 404, de 10 de agosto de 2008. Propõe a retirada das notas de esclarecimento dos itens relacionados com cuidados de saúde a serem disponibilizados aos voluntários e ao uso de placebo na DoH 2008. [Internet]. 2008 [acesso 25 ago 2014]. Disponível: http://conselho.saude.gov.br/resolucoes/2008/Reso_404.doc

17. Garrafa V, Lorenzo C. Helsinque 2008: redução de proteção e maximização de interesses privados. Rev Assoc Med Bras. 2009;55(5):497-520.

18. Greco DB. Emancipação na luta pela equidade em pesquisas com seres humanos. Rev. bioét. (Impr.). 2013;21(1):20-31.

19. Kottow M. De Helsinki a Fortaleza: una Declaración desangrada. Rev. bioét. (Impr.). 2014;22(1):28-33.

20. Associação Médica Brasileira. A questão do placebo: posição da AMB. JAMB. 2008;49(1.357):31-3.

21. Associação Médica Brasileira. Assembleia Anual da Associação Médica Mundial volta ao Brasil depois de 37 anos. JAMB. 2013;54(1.387):6-9.

22. $4^{\text {th }}$ World Conference on Research Integrity; 31 may-3 jun 2015; Rio de Janeiro. [Internet]. [acesso 2 set 2014]. Disponível: http://wcri2015.org/index

23. First Brazilian Meeting on Research Integrity, Science and Publication Ethics; 13-16 dec 2010; Rio de Janeiro. [Internet]. [acesso 2 set 2014]. Disponível: http://www.ibrispe.coppe.ufrj.br

24. Second Brazilian Meeting on Research Integrity, Science and Publication Ethics; 28 may-1 jun 2012; Rio de Janeiro, São Paulo, Porto Alegre. [Internet]. [acesso 2 set 2014]. Disponível: http:// www.iibrispe.coppe.ufrj.br

25. Santos LHL. Sobre a integridade ética da pesquisa. Fapesp. [Internet]. abr 2011 [acesso 2 set 2014]. Disponível: http://www.fapesp.br/6566

26. Associação Médica Brasileira (AMB). Uso do placebo: aspectos bioéticos [editorial]. Rev Assoc Med Bras. 2002;48(3):183-201.

27. Conselho Nacional de Desenvolvimento Científico e Tecnológico (CNPq). Comissão de Integridade de Pesquisa do CNPq. Relatório ética e integridade na prática científica. [Internet]. 7 out 2011 [acesso 26 ago 2014]. Disponível: http://www.memoria.cnpq.br/normas/lei_po_085_11. htm\#etica

28. Fundação de Amparo à Pesquisa do Estado de São Paulo. Código de Boas Práticas Científicas. [Internet]. Fapesp; 16 set 2011 [acesso 26 ago 2014]. Disponível: http://www.fapesp.br/ boaspraticas/codigo_050911.pdf

29. Spink PK. Ética na pesquisa científica. GV-executivo. [Internet]. 2012 [acesso 26 ago 2014];11(1):3841. Disponível: http://rae.fgv.br/sites/rae.fgv.br/files/artigos/38-41_0.pdf

30. Conselho Federal de Medicina. Resolução no 2.056, de 12 de novembro de 2013. Disciplina os departamentos de fiscalização nos Conselhos Regionais de Medicina, estabelece critérios para a autorização de funcionamento dos serviços médicos de quaisquer naturezas.[Internet]. 12 nov 2013 [acesso 28 ago 2014]. Disponível: http://www.portalmedico.org.br/resolucoes/ CFM/2013/2056_2013.pdf

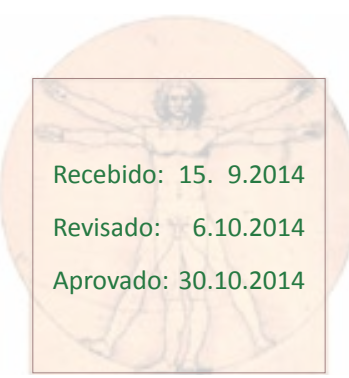




\section{Declaración de Pachuca sobre la revisión de Helsinki}

\section{Confederación Médica Latinoamericana y del Caribe}

La Confederación Médica Latinoamericana y del Caribe, reunida en su XVI Asamblea General Ordinaria en la ciudad de Pachuca los días 20, 21, 22 y 23 de noviembre de 2013, con la presencia de delegados de las organizaciones médicas de Argentina, Bolivia, Brasil, Costa Rica, El Salvador, Guatemala, Honduras, Panamá, Paraguay, Perú, México, Uruguay, Venezuela y España como organización invitada; en relación a la revisión de la declaración de Helsinki aprobada por la Asamblea Anual de la Asociación Médica Mundial donde se han actualizado los criterios éticos que deben guiar la investigación con seres humanos,

\section{Declara en forma unánime:}

a) Pese al trabajo de las Asociaciones miembro de CONFEMEL y FIEM en el grupo de trabajo sobre la revisión de la Declaración de Helsinki y el reconocimiento a algunas modificaciones logradas, se reafirma en todos sus términos la Declaración de Bogotá, adoptada por la XV Asamblea Ordinaria de CONFEMEL donde se rechaza rotunda y unánimemente cualquier investigación médica en seres humanos que utilice el placebo cuando exista una medicación de eficacia demostrada para la patología en estudio. Las poblaciones pobres y vulnerables, discriminadas por su falta de recursos no pueden ser sometidas a investigaciones biomédicas que cuenten con ni- veles de seguridad inferiores a los aplicados a las sociedades con mayor desarrollo;

b) En relación al punto 28 , vinculados al consentimiento informado, se entiende que se comprometió el principio ético del consentimiento y la realidad legal del mismo, no garantizando el respeto a principios y derechos fundamentales como la dignidad, la libertad e intimidad de los seres humanos;

c) En lo que refiere al punto 33, la utilización de placebo cuando existen intervenciones probadas y efectivas es contraria a los principios y valores de la profesión y de la ética médica;

d) Es por lo enunciado anteriormente que lamenta profundamente, y no asume como propia la redacción de los puntos 28 y 33 de la 7ạ edición de la Declaración de Helsinki;

e) Como acción inmediata se propone a los respectivos gobiernos no autorizar ni financiar los medicamentos que hayan utilizado en su evaluación placebo existiendo mejores intervenciones probadas;

f) Las Asociaciones miembro nos comprometemos a denunciar esta situación en todas las instancias y foros nacionales e internacionales así como ante nuestros gobiernos y a realizar todas las acciones institucionales de CONFEMEL para impedir la aplicación de esta norma en la investigación Médica;

g) Asumimos el compromiso de continuar trabajando para lograr la modificación de la actual redacción de la Declaración de Helsinki.

México, 22 de Noviembre de 2013. Argentina, Bolivia, Brasil, Costa Rica, Guatemala, Honduras, México, Panamá, Paraguay, Perú, El Salvador, Uruguay, Venezuela y España 